\title{
Solubilization and Display of G Protein- Coupled Receptors on Beads for Real-Time Fluorescence and Flow Cytometric Analysis
}

BioTechniques 28:976-985 (May 2000)

\author{
L.A. Sklar, J. Vilven, E. \\ Lynam, D. Neldon, T.A. \\ Bennett and E. Prossnitz \\ University of New Mexico, \\ Health Sciences Center, \\ Albuquerque, NM, USA
}

\begin{abstract}
$G$ protein-coupled receptors (GPCR) and cellular signaling elements are prime targets for drug discovery. Sensitive realtime methods that expand the analytical capabilities for these elements can play significant roles in basic research and drug discovery. Here, we describe novel approaches for the real-time fluorescence analysis of GPCRs. Using the G proteincoupled $N$-formyl peptide receptor (FPR) as a model system in concert with a fluorescent ligand, we showed the quantitative solubilization of his-tagged FPRs in 1\% dodecyl maltoside. Solublized receptors reconstitute in dodecyl maltoside with a mixture of bovine brain $G_{i} / G_{o}$ showing an apparent $K_{d}$ of $100 \mathrm{nM}$. Solubilized receptors were also bound to $\mathrm{Ni}^{2+}$-silica particles and were detected in a flow cytometer by the binding of fluorescent ligand. The efficiency of receptor uptake by the particles was in excess of $80 \%$ with an apparent affinity for the bead in the $n M$ range. The receptors had largely homogeneous dissociation characteristics, an appropriate $K_{d}$ for the ligand in the low $n M$ range and a high site number, with several million receptor molecules per particle. However, the $G$ protein reconstitution was not detected on the beads, apparently for steric reasons. These approaches for displaying receptors could prove useful in drug discovery and in the analysis of the molecular assemblies in signal transduction.
\end{abstract}

\section{INTRODUCTION}

Cell surface receptors undergo a number of extracellular and intracellular molecular assemblies important in cell physiology. For G protein-coupled receptors (GPCRs), the assemblies include interactions with ligands, heterotrimeric $\mathrm{G}$ proteins, receptor kinases, arrestin-like molecules and cytoskeletal components, $\mathrm{SH} 2$ domain or PDZ domain proteins, small GTP-binding proteins and polyproline binding proteins $(4,6,7,9,13)$. These interactions may occur transiently during the course of ligand binding, cell activation, receptor desensitization and receptor internalization.

Receptor molecular assemblies are now being explored with a variety of techniques including yeast two-hybrid and phage display in addition to the more traditional biochemical assays. Broken cell preparations utilizing membranes and permeabilized cells are commonly used to allow access of molecular partners to both intracellular and extracellular receptor faces. In both soluble receptor and reconstitution assays, receptor purification by ligand affinity chromotography or epitope tags is routine $(14,17)$. The reconstitution assays use phospholipid vesicles following solubilization (5). Structural analyses of GPCR molecular interactions with G proteins are often accomplished by transfecting cells with the individual transduction elements in both wild-type and mutant forms and examining cell responses (1).

We have previously described a number of real-time assays of ligand-receptor interactions using flow cytometry and fluorescence that have been primarily directed toward viable cells or detergent-permeabilized cells $(2,10$, $15)$. These studies have led to a model of receptor-G protein coupling for the formyl peptide receptor (FPR) (10). In addition, we have recently described a general approach by which molecular assemblies could be analyzed by flow cytometry on beads (12) and a theory by which resonance energy transfer could be used in micelles to analyze geometric and stoichiometric aspects of molecular assemblies (8). If these elements could be used in concert to produce homogeneous "noncellular" receptor displays, then they would be ideal for the analysis of stoichiometry, affinity and kinetics, as well as the elucidation and characterization of signal transduction complexes. Moreover, if they could be made compatible with high-throughput screening strategies, then they would be ideal for drug discovery (11).

We report here a novel means to isolate and analyze receptors in the same single-step procedure. Following the preparation of membranes from transfected cells expressing C-terminally hexahistidine-tagged (C-his) FPRs, the receptors are solubilized in 1\% dodecyl maltoside (3). We are able to assess the efficiency of solubilization using realtime bulk fluorescence methods and demonstrate that the solubilization is quantitative and that the solubilized receptors reconstitute with $\mathrm{G}$ proteins. After incubation with $\mathrm{Ni}^{2+}$-NTA (nitriloacetic acid)-silica particles, the particle-associated receptors are detected in the flow cytometer by the binding of a fluorescent peptide ligand to the particle-bound receptor. The efficiency of receptor uptake by the particles is high with a high number of receptors per particle. The displayed receptors have nearly homogeneous dissociation char- 
acteristics with a $\mathrm{K}_{\mathrm{d}}$ value appropriate for the expected form of the receptor. These displays should complement the existing approaches for identifying and characterizing the interactions of GPCRs with molecular partners.

\section{MATERIALS AND METHODS}

\section{Reagents and Cell Culture}

Plasticware was obtained from VWR Scientific Company (West Chester, PA,
USA). Chemicals and reagents were obtained from Sigma (St. Louis, MO, USA) except where otherwise noted. U937 cells (human histiocytic lymphoma) (16) were obtained from ATCC (Rockville, MD, USA). Cells were grown in tissue culture treated flasks (Corning, Corning, NY, USA) in RPMI 1640 (Hyclone, Logan, UT, USA) containing $10 \%$ fetal bovine serum (FBS), 2 $\mathrm{mM}$ L-glutamine, $10 \mathrm{mM}$ HEPES, with $10 \mathrm{U} / \mathrm{mL}$ penicillin and $10 \mu \mathrm{g} / \mathrm{mL}$ streptomycin. Cultures were grown in standard tissue culture incubators at $37^{\circ} \mathrm{C}$

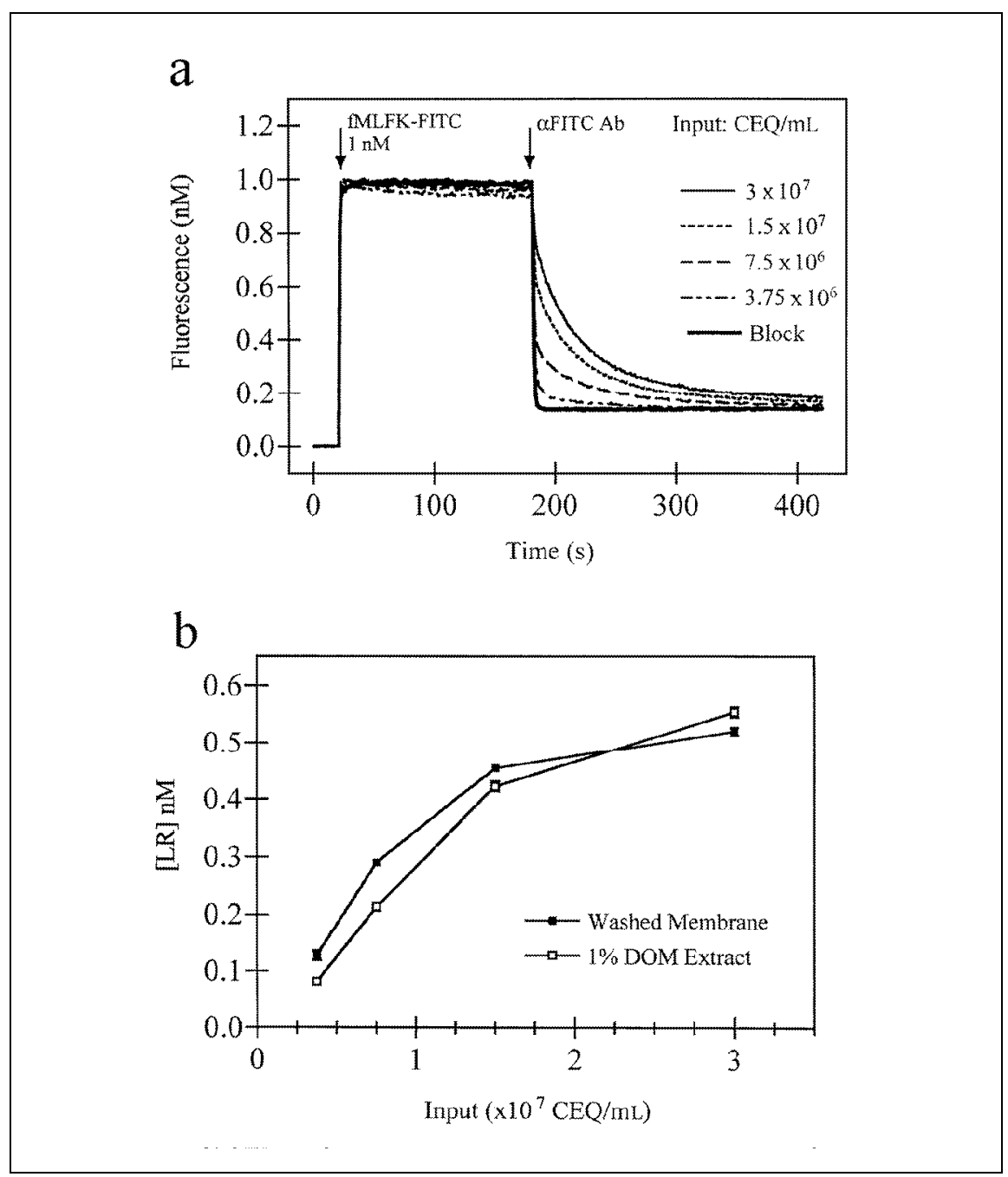

Figure 1. Characterization of ligand binding to solubilized C-His FPR and membranes. (a) Spectrofluorometric analysis of ligand binding to and dissociation from FPR. fMLFK-FITC (1 nM) was incubated with C-his FPR from U937 membranes extracted with 1\% dodecyl maltoside. Binding is detected as residual fluorescence following addition of antibody to fluorescein. Data for each separate curve represent a varied receptor input expressed as $\mathrm{CEQ} / \mathrm{mL}$. (b) Comparison of the amount of ligand bound in the assay for membranes and solubilized membrane extracts (determined as in panel A) as a function of the amount of membrane used. [Note that if $20 \%$ of the cellular receptors (about $300000 /$ cell) are recovered in the membrane preparation and solubilization steps, $10^{7} \mathrm{CEQ} / \mathrm{mL}$ would provide about $1 \mathrm{nM}$ receptors]. The results are representative of experiments repeated at least twice.

with $5 \% \mathrm{CO}_{2}$ and passaged from subconfluent cultures every 2-3 days by reseeding at $2 \times 10^{5}$ cells $/ \mathrm{mL}$.

\section{Expression of C-his FPR by Transfected U937 Cells}

The hexahistidine tag was incorporated into a C-terminal oligonucleotide. This oligonucleotide was used in conjunction with an N-terminal oligonucleotide and Pfu DNA polymerase for PCR amplification of the FPR. Automated dideoxy sequencing was performed to confirm the sequence. The receptor-tagged constructs were transfected into U937 cells by electroporation and selected with G418. The transfected cells were identified by fluorescent peptide binding and sorted by flow cytometry. In typical preparations, the receptor density was determined using fluorescent peptide and flow cytometry to be about 300000 receptors/cell (2).

\section{Membrane Preparation by $\mathbf{N}_{2}$ Cavitation}

U937 C-His FPR cells were harvested, centrifuged at $200 \times g$ for $5 \mathrm{~min}$ and resuspended in cavitation buffer at a density of $10^{7}$ cells $/ \mathrm{mL}$ at $4^{\circ} \mathrm{C}(10 \mathrm{mM}$ PIPES, $100 \mathrm{mM} \mathrm{KCl,} 3 \mathrm{mM} \mathrm{NaCl}, 3.5$ $\mathrm{mM} \mathrm{MgCl} 2,600 \mu \mathrm{g} / \mathrm{mL}$ ATP, $50 \mu \mathrm{M}$ PMSF and $20 \mu \mathrm{g} / \mathrm{mL}$ chymostatin. The cell suspension was placed in a nitrogen bomb and pressurized to $450 \mathrm{psi}$ using $\mathrm{N}_{2}$ gas for $20 \mathrm{~min}$ at room temperature. Unlysed material was separated by centrifugation at $1000 \times g$ for 5 $\min$ at $4^{\circ} \mathrm{C}$. The supernatant, containing membranes, was washed $2 \times$ by centrifugation at $135000 \times g$ for $30 \mathrm{~min}$ at $4^{\circ} \mathrm{C}$, then resuspended in HEPES sucrose buffer [200 mM sucrose, $25 \mathrm{mM}$ HEPES ( $\mathrm{pH} 7.0$ )], aliquoted and stored until use at $-80^{\circ} \mathrm{C}$.

\section{Solubilization of C-His FPR}

Membranes were thawed and diluted to $1-2 \times 10^{8}$ membrane cell equivalents/ $\mathrm{mL}(\mathrm{CEQ} / \mathrm{mL})$ in binding buffer (30 mM HEPES, $100 \mathrm{mM} \mathrm{KCl}, 20 \mathrm{mM}$ $\mathrm{NaCl}, 1 \mathrm{mM}$ EGTA, $0.1 \% \mathrm{w} / \mathrm{v}$ BSA, 0.5 $\mathrm{mM} \mathrm{MgCl} 2$ and $1 \mathrm{mM}$ PMSF). Preparations were maintained at $4^{\circ} \mathrm{C}$ throughout the extraction process. Membranes were centrifuged at $135000 \times g$ for $30 \mathrm{~min}$ and 
resuspended to $6 \times 10^{8} \mathrm{CEQ} / \mathrm{mL}$ in binding buffer containing a broad protease inhibitor cocktail (CalbiochemNovabiochem, San Diego, CA, USA) and $1 \% \mathrm{n}$-dodecyl $\beta$-D-maltoside. Preparations were incubated for $1 \mathrm{~h}$ at $4^{\circ} \mathrm{C}$ with agitation. The insoluble fraction was separated by centrifugation at $87750 \times g$ for $30 \mathrm{~min}$. The supernatant was removed, and this extract was used for experimentation within $6 \mathrm{~h}$.

\section{Reconstitution of Receptors with G Proteins}

FPR (10 nM final concentration) in $1 \%$ dodecyl maltoside as above was incubated with a mixture of bovine brain $\mathrm{G}_{\mathrm{i}} / \mathrm{G}_{\mathrm{o}}$ in a final volume of $10-20 \mu \mathrm{L}$ (Calbiochem-Novabiochem) at a concentration of up to $300 \mathrm{nM}$ for up to $2 \mathrm{~h}$ on ice in the presence of about $10 \mathrm{nM}$ formyl-met-leu-phe-lys-FITC (fMLFKFITC; Peninsula Laboratories, Belmont, CA, USA). The samples were analyzed by the spectrofluorometric approach described below.

\section{Affinity Conjugation of C-His FPR Extract with $\mathrm{Ni}^{2+}$-NTA Silica Particles}

To affinity-couple FPRs to a particulate substrate, $\mathrm{Ni}^{2+}$-NTA-coated silica particles (Qiagen, Valencia, CA, USA) were added to U937 C-His FPR membrane extracts at $10 \mathrm{mg} / \mathrm{mL}$ and incubated at $4^{\circ} \mathrm{C}$ for $30 \mathrm{~min}$ with gentle mixing. This concentration of silica produced $1.15 \times 10^{6}$ silica particles $/ \mathrm{mL}$ as measured using a hemacytometer. Silica particles ranged from approximately 2-20 $\mu \mathrm{m}$ in diameter with random nonspherical shapes. Since silica particles settle rapidly from suspension, samples required gentle resuspension by inversion or pipetting at each handling step.

\section{Spectrofluorometric Analysis}

Fluorescence associated with fMLFK-FITC was measured by a SLM 8000 spectrofluorometer (Spectronic Instruments, Rochester, NY, USA) using the photon counting mode in acquisition. The sample stage was fitted with a cylindrical cuvette adapter to permit measurements in stirred volumes of $200 \mu \mathrm{L}$ using small cylindrical cuvettes
(Sienco, Morrison, CO, USA) and $2 \times$ 5-mm stir bars (Bel-Art, Pequannock, NJ, USA). Excitation was fixed at 490 $\mathrm{nm}$, and stray light was reduced with a 490-nm, 10-nm band pass filter (Corion, Holliston, MA, USA). FITC fluorescence emission was monitored using a $520-\mathrm{nm}, 10-\mathrm{nm}$ band pass interference filter (Corion) and a 3-70 organic glass, $500 \mathrm{~nm}$ long pass filter (Kopp, Pittsburgh, PA, USA). Additions to samples during kinetic measurements were performed using $5-25-\mu \mathrm{L}$ glass syringes (Hamilton, Reno, NV, USA) adding reagents through an injection port on the SLM 8000 spectrofluorometer above the sample cuvette.

Following preparation at $4^{\circ} \mathrm{C}$, samples were equilibrated to $22^{\circ} \mathrm{C}$ and placed into the spectrofluorometer with constant stirring. Data were acquired for $200-420 \mathrm{~s}$ in 1-s intervals. Typically, background fluorescence was obtained for the first $20 \mathrm{~s}$, fMLFK-FITC was added and fluorescence was measured to $180 \mathrm{~s}$. Then, an anti-fluorescein $(\mathrm{Ab})$ was added to the sample. The $\mathrm{Ab}$ binds fMLFK-FITC with high affinity and results in essentially complete quenching of fluorescence associated with free ligand (15). Thus, the re- maining fluorescence represents the bound fraction and may be used to estimate the concentration of bound ligand. In $\mathrm{G}$ protein experiments, GTP $\gamma \mathrm{S}$ sensitivity was used to assess the coupling between receptors and $\mathrm{G}$ proteins based on characteristic ligand dissociation rates. Determination of the concentration of fluorescent peptide and the calibration of peptide fluorescence have been described previously (2). Briefly, these involve: $(i)$ measuring the absorbance of the peptide at $490 \mathrm{~nm}$, then determining concentration as a function of the extinction coefficient and (ii) adjusting peptide fluorescence to fluorescein equivalents based on the relationship of 0.8 fluorescein equivalents/ fMLFK-FITC. Controls included samples in which binding of fluorescent ligand was blocked by an excess of prebound tBoc-phe-leu-phe-leu-phe (Vega Biochemicals, Tucson, AZ, USA) and samples containing no receptor extract.

Analysis of kinetic binding data involved the determination of ligand-specific fluorescence by subtraction of the mean baseline from each sample, normalization to the peak fluorescence and expression of normalized data relative to matched control values. Data were

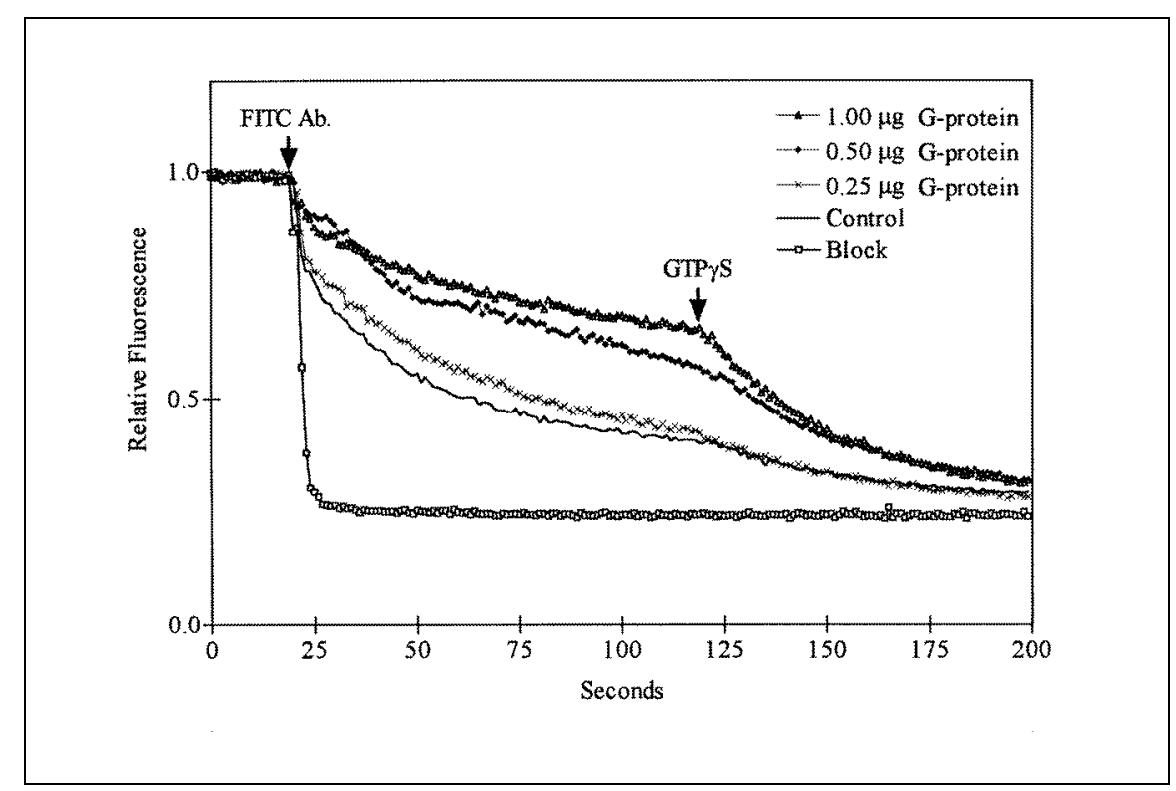

Figure 2. Reconstitution of $G$ protein to receptor in dodecyl maltoside. The relative fluorescence of bound ligand is shown vs. time. Solubilized receptors, approximately $10 \mathrm{nM}$ in $20 \mu \mathrm{L}$, were incubated with $10 \mathrm{nM}$ fMLFK-FITC and G protein for $2 \mathrm{~h}$ at $4^{\circ} \mathrm{C}$. The mixture was diluted to $200 \mu \mathrm{L}$ for the binding analysis. The intensity is shown for several concentrations of $\mathrm{G}$ protein before the addition of antibody to fluorescein, after antibody addition $(a t t=20 \mathrm{~s}$ ), and after addition of GTP $\gamma \mathrm{S}$ (at $\mathrm{t}=120 \mathrm{~s}$ ). The change in the ligand dissociation characteristics after GTP $\gamma \mathrm{S}$ addition reflects the extent of reconstitution to $\mathrm{G}$ protein. 

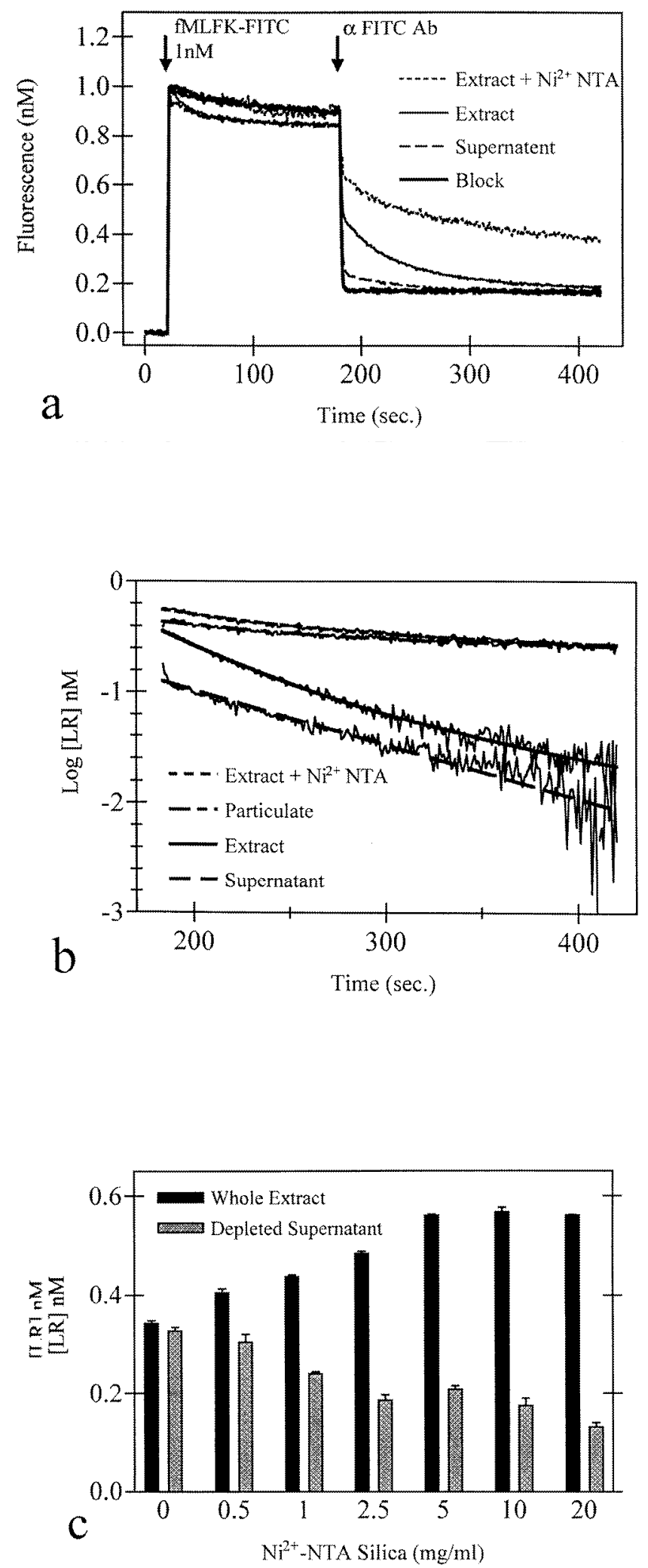

analyzed and graphed using Prism software (Graph Pad Software, San Diego, CA, USA). To determine the dissociation characteristics of the receptor preparations, the fluorescence over time in blocked control samples was subtracted point by point from the fluorescence over time of ligand binding samples as described previously (15). The resulting curves (Figure $3 b$ ) reflect the ligand dissociation rates, and the linearity reflects homogeneous dissociation. There is an artifact in the first few seconds of the dissociation caused by the non-instantaneous reactivity of the antibody that can be ignored here.

\section{Flow Cytometric Analysis}

Experiments to assess the efficiency of coupling the soluble C-his FPR to $\mathrm{Ni}^{2+}$-NTA silica particles and the relative affinity of the receptor on the particle for ligand were performed using a FACScan $^{\mathrm{TM}}$ flow cytometer (Becton Dickinson, Franklin Lakes, NJ, USA). Ten thousand events were analyzed per sample, using a threshold on forward angle light scatter and forward angle versus $90^{\circ}$ light scatter dot plot gating

Figure 3. The efficiency of display of solubilized receptors on particles. (a) The uptake of $\mathrm{C}$ His FPR onto $\mathrm{Ni}^{2+}$-NTA silica particles was demonstrated by the depletion of receptor from FPR extracts. The experiments were performed with $1 \mathrm{nM}$ fMLFK-FITC, $1.5 \times 10^{7} \mathrm{CEQ} / \mathrm{mL}$ membrane and $20 \mathrm{mg}$ silica particles $/ \mathrm{mL}$. The spectroscopic analysis used the antibody to fluorescein to examine ligand binding. The binding curves are depicted from top to bottom: receptors present on silica particles; receptors present in the membrane extract; receptors present in the supernatant after silica particles have been removed from the extract; and control sample, in which a blocking peptide (10 $\mu \mathrm{M}$ tboc-phe-leu-phe-leuphe) inhibits the specific binding. (b) Dissociation rates are determined from panel $b$ by subtracting the nonspecific binding in the blocked control from the specific binding and replotting the data on a semi-log scale. From top to bottom, the curves are: the ligand dissociation from receptors in the membrane extract in the presence of the silica partices; the ligand dissociation in the particulate fraction of the extract after pelleting by centrigation and resuspension; the ligand dissociation from solublized receptors; and the ligand dissociation from the supernatant of particles and solubilized receptors. (c) The relative amount of ligand binding to particle-associated receptors and nonparticle-associated receptors as a function of the amount of particles present. The results are representative of experiments repeated twice. 
to resolve the primary population of silica particles. Data was collected from FL1 (FITC fluorescence) in log mode with no spectral compensation. Affinity-coupled C-His FPR-Ni ${ }^{2+}$ NTA samples were prepared as described, by varying either the relative receptor input with a constant fMLFK-FITC concentration or by varying the fMLFK-FITC concentration with a constant input of receptor, $1.5 \times 10^{7} \mathrm{CEQ} / \mathrm{mL}$. Samples were prepared and analyzed at $4^{\circ} \mathrm{C}$. Controls included silica particles with no receptor in the presence or absence of fMLFK-FITC and samples in which the binding of fMLFK-FITC was inhibited by preblocking with tBoc-phe-leuphe-leu-phe or F-met-leu-phe-phe-glygly-lys. We report specific, mean fluorescence in each sample, calculated using Prism software by subtracting sample-matched controls. Site numbers were estimated by linear regression analysis of fluorescence values associated with quantitative bead standards (Quantum 25P; Flow Cytometry Standards Corporation, San Juan, Puerto Rico). Peptide-FITC fluorescence was adjusted to fluorescein equivalents (2).

\section{RESULTS AND DISCUSSION}

Our experimental approach uses a fluorescence method to analyze ligand binding and dissociation with membranes and solubilized receptors. The method involves a fluoresceinated ligand and an antibody to the fluorescein that discriminates free and receptorbound ligand by rapidly quenching the fluorescence of the free ligand. The receptor-bound ligand is not recognized by the $\mathrm{Ab}$. As a ligand dissociates, it is rapidly bound and quenched by the $\mathrm{Ab}$. The quantity of receptor-bound peptide can be determined as the observed fluorescence of the sample immediately following addition of the anti-fluorescein antibody. Figure 1a shows the behavior of the membrane extract in an assay with $1 \mathrm{nM}$ fluoresent formyl peptide as a function of receptor input. The results for the original membrane preparation and the detergent extract are compared in Figure 1b. The extent of ligand binding is similar for the membranes and the soluble membrane extract as a function of the receptor input.
The affinity between receptors and $\mathrm{G}$ proteins is difficult to assess directly in cells or membranes. Figure 2 shows that the receptors and $\mathrm{G}$ protein readily reconstitute in dodecyl maltoside. This is characterized by the appearance of slow ligand dissociation and the sensitivity of the ligand dissociation rate to the presence of guanine nucleotide. The $\mathrm{ED}_{50}$ for the reconstitution is $100 \mathrm{nM}$ under conditions where the receptor and ligand concentrations are approxi-

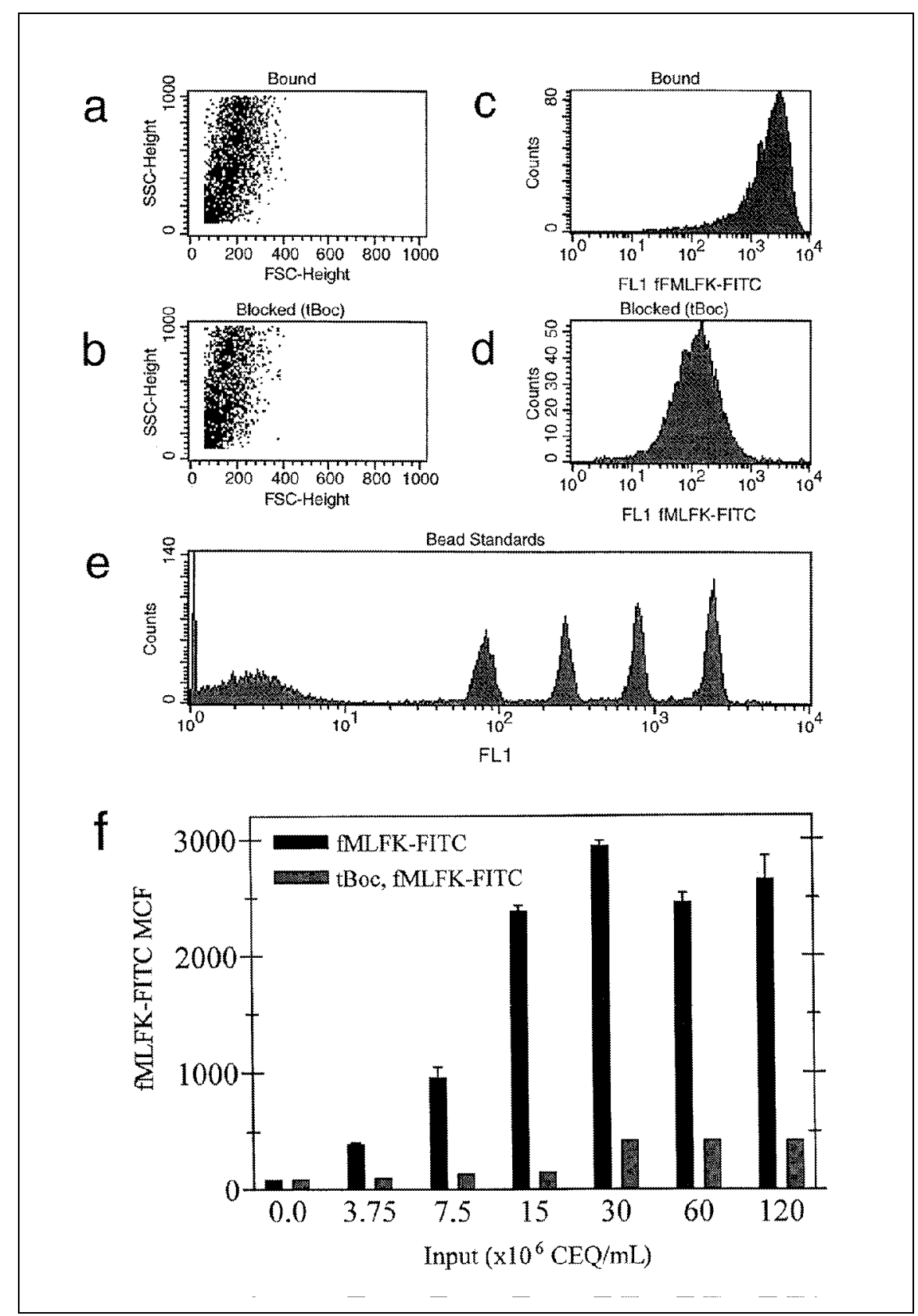

Figure 4. Quantitation of ligand binding to receptors on particles. Light scatter characteristics of silica particles by flow cytometry in the presence of specific (a) and nonspecific (b) ligand binding. Fluorescence histograms of specific (c) and nonspecific (d) ligand binding compared to fluorescence histograms (e) of quantitative bead standards. The five bead populations are reported to represent 0,48900 , 87400,552000 , and 1510000 fluorescein equivalents. Experiments were performed with $10 \mathrm{nM}$ fMLFK-FITC, $10 \mathrm{mg} / \mathrm{mL}$ silica particles and $1.5 \times 10^{7} \mathrm{CEQ} / \mathrm{mL}$. The blocking peptide t-boc-phe-leuphe-leu-phe was used at $10 \mu \mathrm{M}$. (f) Specificity of ligand binding with varied receptor input. The mean channel fluorescence (MCF) values are on the same scale as in panels c, $d$ and e. The results are representative of experiments performed at least three times. 
mately $10 \mathrm{nM}$. Because the bulk of the $\mathrm{G}$ protein is not depleted by binding to the receptor, the $\mathrm{ED}_{50}$ represents an upper limit for the $\mathrm{K}_{\mathrm{d}}$. We have not established in a mixture of $G$ proteins whether all of the subtypes bind to the receptors. In the event that the binding represents only one of the subtypes, the $\mathrm{K}_{\mathrm{d}}$ would be further reduced.

The next set of experiments shows that the solubilized receptors could be displayed on silica particles in a format compatible with flow cytometry. Figure 3 a shows a receptor recovery assay in which the particles were incubated with solubilized receptors. The results show that in the presence of the particles, receptors can be quantitatively sedimented out of the bulk phase. Binding of ligand to the particle-bound receptors results in an increased ligand binding signal (due to slower ligand dissociation and a higher binding affinity).

Figure $3 \mathrm{~b}$ compares the ligand-receptor dissociation characteristics for receptors on the particles and in suspension. Based on the nearly linear rate of dissociation, the receptors displayed on the particles are essentially homogeneous, with less than $10 \%$ of the recep-

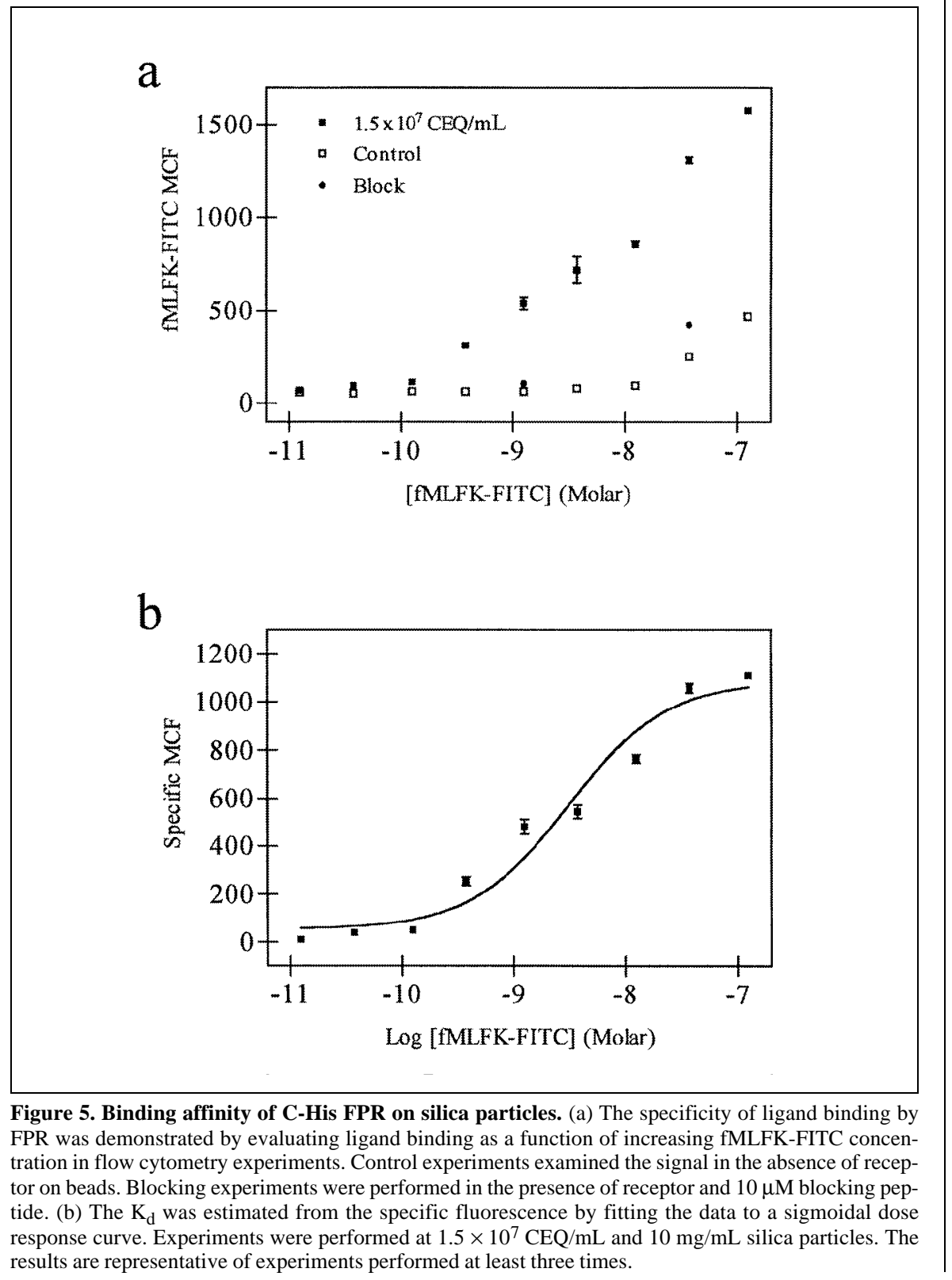


tors on beads dissociating at the rapid rate characteristic of receptors not on beads. The small fraction of rapidly dissociating receptors in the preparation of sedimented and resuspended particles could arise from slow release of receptors from the particle surface.

Figure $3 c$ shows the uptake of receptors by the particles as a function of the particle density. The increase in total ligand binding compared to the membrane extract, as more $\mathrm{Ni}^{2+}-\mathrm{NTA}$ is added, is a consequence of the increase in ligand affinity seen in Figure 3a. About half of the receptor (approximately $0.2-0.3 \mathrm{nM}$ ) is bound by the silica particles at a concentration as low as $1 \mathrm{mg} / \mathrm{mL}$ particles. More than $80 \%$ of the receptor is bound at $20 \mathrm{mg} / \mathrm{mL}$ particles. The reported binding capacity of the particles is approximately 500 $\mathrm{pmol} / \mathrm{mg}$, indicating that excess unused binding sites on the particles are present. Since the number of receptor bind- ing sites on the particles represents several million per particle (or roughly 0.3-0.5 nM under our conditions) (Figure 4), the amount of receptor displayed on the particle depends on the receptor input relative to the particle density (Figure 3c). The level of receptor remaining in the supernatant is consistent with a $K_{d}$ in the $n M$ range between the his-tagged receptor in detergent and the $\mathrm{Ni}^{2+}-\mathrm{NTA}$ binding sites on the particle. It is compatible with the release of receptor from the surface under the conditions described here (Figure $3 b$ ).

Having demonstrated that $\mathrm{Ni}^{2+}$ NTA particles could be used to deplete extracts of the FPR, we worked to determine whether these receptor-bound particles could be analyzed by flow cytometry. Figure 4 shows the flow cytometric characterization of receptors displayed on the silica particles. The flow cytometric dot plot of $90^{\circ}$ light scatter (SSC) vs. forward angle light scatter (FSC) shows that the particles are heterogeneous (Figure 4, a and b). However, the FL1 histogram data shows that there is specific ligand binding (Figure 4c), compared to the nonspecific binding signal obtained when antagonist is present (Figure 4d). An estimate of the number of receptors displayed per particle has been made using calibration standards for fluorescein-labeled ligands (Figure 4e) using methods described previously $(2,15)$. The average number of fluorescein equivalents per particle is about 1.5 million, similar to the highest standard. To convert flow cytometer data to ligand binding measurements (5), the relative fluorescence of free fluorescein compared to conjugated FITC $(85 \%)$ and the quenching upon binding to the receptor must be taken into account. The number of receptors occupied at particle saturation is therefore estimated to be about 2 million. Considering 
the $\mathrm{K}_{\mathrm{d}}$ and the ligand concentration, as described in Figure 4, the total number of binding sites per particle is about 3 million. Under optimal conditions, a fluorescent ligand signal-to-background ratio of at least 30:1 can be obtained (Figure 4f). The optimal signal is obtained by varying the input of the receptor at fixed particle density, with the signal saturating at an input of receptor above 10-15 million CEQ/mL.

Further characterization of the receptors was accomplished by examining the specific and nonspecific binding at varying ligand concentration. Since the receptor $K_{d}$ is about $3 \mathrm{nM}$ and the off-rate is about 0.03/s (Figure 3), the predicted on-rate is approximately $10^{7} / \mathrm{M} / \mathrm{s}$ at room temperature. This onrate is consistent with previously reported cellular values extrapolated from slightly higher physiological temperatures (2). The $\mathrm{K}_{\mathrm{d}}$ and off-rates are a function of the specific ligand and the state of the receptor. The values are similar to those reported in permeabilized neutrophils when guanine nucleotide has been added to uncouple the receptor-G protein complex. Both $\mathrm{N}$ his (not shown) and C-his receptors are able to bind ligands, suggesting there is no intrinsic steric interference when either the amino terminus region of the receptor (the extracellular face) or the carboxy terminus (intracellular face of the receptor) is close to the particle surface (Figure 5). The C-his receptor binds to beads in the presence of $\mathrm{G}$ protein but does not reconstitute with $G$ proteins on the bead. This could result from the relative affinities of the ternary complex interaction (ligand, receptor, $\mathrm{G}$ protein) compared to the ligand, receptor, bead interaction and the steric interference caused by the attachment of the carboxy terminal tail to the bead. Pilot studies found that the N-his receptor has such high affinity and low dissociation rate for the ligand that its dissociation rate was not readily discriminated in either the presence or absence of $G$ protein or of beads.

In summary, we have described a receptor solubilization in which C-terminally his-tagged FPRs are solubilized quantitatively, readily analyzed by sensitive real-time ligand binding and reconstituted with $G$ protein. The affinity of the reconstitution was determined to be approximately $100 \mathrm{nM}$. The solubilized receptors are efficiently taken up on a particle surface at high number and displayed with an appropriate $\mathrm{K}_{\mathrm{d}}$ and a near homogenous off-rate. Soluble Nterminally his-tagged FPRs have also been used to display receptors on particles (not shown).

The use of quantitative flow cytometry and energy transfer promises to be valuable in the analysis of both molecular conformation and stoichiometry. These approaches are compatible with other bead chemistries and high-throughput screening. Moreover, they will be of significantly higher benefit to the scientific community when $\mathrm{Ni}^{2+}$ beads, which are more homogeneous than these silica particles, are commercially available as receptor display systems.

\section{ACKNOWLEDGMENTS}

This work was supported by the New Mexico Cancer Research Fund, RR01315, to L.A.S. and NIH grant nos. NIAID36357 and NIAID43932 and an AHA grant-in-aid to E.R.P., and NIH grant no. IRZ4GM60799 to L.A.S. and E.R.P.

\section{REFERENCES}

1.Bourne, H.R. 1997. How receptors talk to trimeric G proteins. Curr. Opin. Cell. Biol. 9:134-142.

2.Fay, S.P., R.G. Posner, W.N. Swann and L.A. Sklar. 1991. Real-time analysis of the assembly of ligand, receptor and G-protein by quantitative fluorescence flow cytometry. Biochemistry 30:5066-5075.

3.Gether, U., S. Lin and B.K. Kobilka. 1995. Fluorescent labeling of purified beta 2 adrenergic receptor. Evidence for ligand-specific conformational changes. J. Biol. Chem. 270:28268-28275.

4.Gudermann, T., B. Nurnberg and G. Schultz. 1995. Receptors and G proteins as primary components of transmembrane signal transduction. Part 1. G-protein-coupled receptors: structure and function. J. Mol. Med. 73:51-63.

5.Gurevich, V.V., R. Pals-Rylaarsdam, J.L. Benovic, M.M. Hosey and J.J. Onorato. 1997. Agonist-receptor-arrestin, an alternative ternary complex with high agonist affinity. J. Biol. Chem. 272:28849-28852.

6.Hall, R.A., R.T. Premont and R.J. Lefkowitz. 1999. Heptahelical receptor signaling: beyond the $\mathrm{G}$ protein paradigm. J. Cell Biol. 145:927-932.
7.Ji, T.H., M. Grossman and I. Ji. 1998. G protein-coupled receptors: I. Diversity of receptor-ligand interaction. J. Biol. Chem. 273: 17299-17302.

8.Jones, G., C. Wistrom, C. Wofsy and L.A. Sklar. 1999. Analysis of vertical energy transfer in small micelles. Biophys. J. 76:517-528.

9.Lefkowitz, R.J. 1998. G protein-coupled receptors. III. New roles for receptor kinases and beta-arrestins in receptor signaling and desensitization. J. Biol. Chem. 273:1867718680.

10.Nolan, J., J.D. Chambers and L.A. Sklar. 1998. Flow cytometric analysis of ligand-receptor interactions, p. 19-46. In G. Babcock and P. Robinson (Eds.), Cytometric Approaches to Cellular Analysis, Wiley-Liss, New York.

11.Nolan, J.P., S. Lauer, E. Prossnitz and L.A. Sklar. 1999. Flow Cytometry in Drug Discovery. Drug Discovery Today 4:173-180.

12.Nolan, J.P. and L.A. Sklar. 1998. The emergence of flow cytometry for the sensitive, realtime analysis of molecular assembly. Nat. Biotechnol. 16:633-638.

13.Nurnberg, B., T. Gudermann and G. Schultz. 1995. Receptors and G proteins as primary components of transmembrane signal transduction. Part 2. G proteins: structure and function. J. Mol. Med. 73:123-132.

14.Pawate, S., K.L. Schey, G.P. Meier, M.E. Ullian, D.E. Mais and P.V.Halushka. 1998. Expression, characterization, and purification of C-terminally hexahistidine-tagged thromboxane A2 receptors. J. Biol. Chem. 273: 22753-22760.

15.Sklar, L.A., D.A. Finney, Z.G. Oades, A.J. Jesaitis, R.G. Painter and C.G. Cochrane. 1984. Dynamics of ligand-receptor interactions. Real-time cytometric and fluorimetric assays of association, dissociation and internalization of an $\mathrm{N}$-formyl peptide and its receptors on human neutrophils. J. Biol. Chem. 259:5661-5669.

16.Sundstrom, C. and K. Nilsson. 1976. Establishment and characterization of a human histiocytic lymphoma cell line (U-937). Int. J. Cancer 17:565-577.

17.Xiao, Z., Y. Yao, Y. Long and P. Devreotes. 1997. Desensitization of G-protein-coupled receptors. Agonist-induced phosphorylation of the chemoattractant receptor cAR1 lowers its intrinsic affinity for cAMP. J Biol. Chem. 274:1440-1448.

Received 15 September 1999; accepted 2 December 1999.

\section{Address correspondence to:}

Dr. Larry A. Sklar

Cancer Center

2325 Camino de Salud, CRF219A

University of New Mexico

Albuquerque, NM 87131, USA

Internet:lsklar@salud.unm.edu 